\title{
Sodium-controlled Coupling of Respiration to Energy-linked Functions in Pseudomonas stutzeri
}

\author{
By T. KODAMA AND S. TANIGUCHI \\ Department of Biochemistry, Hiroshima University School of Dentistry, \\ Kasumi 1-2-3, Hiroshima 734, Japan
}

(Received I September 1976)

\begin{abstract}
SUMMARY
In the presence of $\mathrm{K}^{+}, \mathrm{Na}^{+}$enhanced respiration and activated cellular motility and transport of $\mathrm{K}^{+}$, amino acids and phosphate in Pseudomonas stutzeri. Inorganic phosphate taken up was rapidly esterified to nucleoside triphosphates and diphosphates. Respiration and phosphate transport showed cooperative responses to $\mathrm{Na}^{+}$ which increased with temperature. Respiration was more sensitive to polymyxin B in the presence of $\mathrm{Na}^{+}$. Dinitrophenol and carbonyl cyanide $p$-trifluoromethoxyphenylhydrazone stimulated respiration when either $\mathrm{Na}^{+}$or $\mathrm{K}^{+}$was absent, but not in the presence of both cations. Therefore, $\mathrm{Na}^{+}$is essential for the cytoplasmic membrane of $P$. stutzeri to perform energy-linked functions coupled to respiration.
\end{abstract}

\section{INTRODUCTION}

Pseudomonas stutzeri is a non-halophilic bacterium requiring $\mathrm{Na}^{+}$irrespective of growth conditions (Kodama \& Taniguchi, 1976). In the presence of $\mathrm{K}^{+}$, respiration was enhanced specifically by $\mathrm{Na}^{+}$. The respiration rate of exponentially growing organisms was a linear function of the growth rate when limited by the $\mathrm{Na}^{+}$concentration. However, the maximum respiration rate induced by excess $\mathrm{Na}^{+}$was independent of the growth rate. One hypothesis that explains these findings is that the cation is essential for coupling of respiration to energy metabolism. If this is valid, cellular functions that require energy would be expected to be $\mathrm{Na}^{+}$-dependent.

We have investigated the coupling of respiration to the generation of metabolic energy in the presence of $\mathrm{Na}^{+}$(plus $\mathrm{K}^{+}$).

\section{METHODS}

Materials. These were obtained as follows: membrane filters, Sartorius; polyethyleneimine (PEI)-cellulose plates and 'Suprapur' grade $\mathrm{NaCl}$ and $\mathrm{KCl}$, Merck; nucleotides, Kyowa Hakko, Tokyo, Japan; carbonyl cyanide $p$-trifluoromethoxyphenylhydrazone (FCCP), a gift from Prof. Y. Kagawa (later purchased from Boehringer-Mannheim); [ ${ }^{32}$ P]orthophosphoric acid, Japan Atomic Energy Research Institute, Tokyo; L-[G- $\left.{ }^{3} \mathrm{H}\right]$ glutamic acid, The Radiochemical Centre, Amersham.

Media. Three basal media were used. TLGP medium contained: I00 mM-Tris; $40 \mathrm{mM}-$ DL-lactic acid; $30 \mathrm{mM}-\mathrm{L}$-glutamic acid; $10 \mathrm{mm-phosphoric} \mathrm{acid;} \mathrm{and} 2 \%(\mathrm{v} / \mathrm{v})$ trace element mixture (Sistrom, I960). The $\mathrm{pH}$ was adjusted with $\mathrm{HCl}$ at room temperature $\left(20\right.$ to $23^{\circ} \mathrm{C}$ ) so that the $\mathrm{pH}$ would be 7.4 at the desired temperature. TLP and TLG media were derived from TLGP medium by omitting glutamic acid and phosphoric acid respectively.

Micro-organisms. Pseudomonas stutzeri (van Niel strain, IAMI2097) was maintained on 
nutrient agar slopes (Kodama, Shimada \& Mori, I969). It was grown at $30^{\circ} \mathrm{C}$ in TLGP medium supplemented with ro $\mathrm{mM}-\mathrm{KCl}$ and $\mathrm{NaCl}$ and growth was measured as previously described (Kodama \& Taniguchi, 1976). Exponentially growing cultures (40 to $60 \mathrm{Klett}$ units) were chilled on ice and centrifuged at $5000 \mathrm{~g}$ for $10 \mathrm{~min}$. Cells were washed three times with one of the three basal media as specified below.

Uptake of $\mathrm{K}^{+}$, glutamate and phosphate. Uptake was measured at $30^{\circ} \mathrm{C}$ using the following membrane filtration method. The bacterial density in the reaction mixtures was 30 to 50 Klett units.

$K^{+}$. Organisms which had been washed with TLGP medium and kept on ice for $15 \mathrm{~h}$ were resuspended in the same medium. After to min pre-incubation, $\mathrm{KCl}$ (final concentration, I $\mathrm{mM}$ ) was added to start the reaction. Samples ( $\mathrm{I} \mathrm{ml}$ ) were transferred at intervals to membrane filters (MF-45, pore size $0.45 \mu \mathrm{m}$ ) and washed with three $2 \mathrm{ml}$ portions of TLGP medium within $30 \mathrm{~s}$. The filters were dried under an infrared lamp and extracted with $\mathrm{I} \mathrm{ml}$ $0.5 \mathrm{M}-\mathrm{HCl}$ at $100^{\circ} \mathrm{C}$ for $30 \mathrm{~min}$. The extracts were centrifuged for $10 \mathrm{~min}$ and the $\mathrm{K}^{+}$concentration in the supernatant was then measured.

Glutamate. The reaction mixture was prepared by diluting the suspension of organisms in TLP medium with the same medium supplemented with chloramphenicol $\left(50 \mu \mathrm{g} \mathrm{ml}^{-1}\right)$ and $5 \mathrm{mM}-\mathrm{KCl}$. The reaction was started by adding $0.3 \mathrm{~mm}-\left[{ }^{3} \mathrm{H}\right]$ glutamic acid $\left(0.6 \mu \mathrm{Ci} \mathrm{ml}^{-1}\right)$. Samples $(0.5 \mathrm{ml})$ were collected on the membrane filters, washed with TLGP medium and then dried as before. The filter was transferred to a scintillation vial for radioactivity measurement.

Inorganic phosphate. Organisms which had been washed with TLG medium were used. The reaction mixture was composed of this medium supplemented with 0.3 to I mM inorganic [32 P]phosphate $\left(\mathrm{PO}_{4}{ }^{3-} ; 20\right.$ to $\left.400 \mu \mathrm{Ci} \mathrm{ml}{ }^{-1}\right) ; 5 \mathrm{~mm}-\mathrm{KCl}$ was added to start the reaction. Samples $(20$ to $100 \mu \mathrm{l})$ were collected on membrane filters, washed with TLGP medium as described for $\mathrm{K}^{+}$uptake and processed as for the glutamate uptake experiments.

Phosphate uptake was expressed as $\mu$ mol phosphate (g dry wt) ${ }^{-1}$. The specific activity of the $\mathrm{PO}_{4}{ }^{3-}$ was calculated from the radioactivity of ${ }^{32} \mathrm{P}$ and the $\mathrm{PO}_{4}{ }^{3-}$ concentration in the reaction mixtures determined by the method of Fiske \& SubbaRow (1925).

Phosphate metabolism. Entry of ${ }^{32} \mathrm{PO}_{4}{ }^{3-}$ into the intracellular phosphate pools was determined by extracting the acid-soluble phosphates with formic acid. The washed filters were immediately soaked in I $\mathrm{ml} 0.5 \mathrm{M}$-formic acid in centrifuge tubes which were agitated for $30 \mathrm{~s}$ on a vortex mixer. The tubes were again agitated after standing on ice for $20 \mathrm{~min}$ before centrifuging at $1000 \mathrm{~g}$ for $\mathrm{I}$ o min to remove acid-insoluble material. Total [ $\left.{ }^{32} \mathrm{P}\right] \mathrm{phos}-$ phate in the extract was estimated by applying a portion of the supernatant to a disc ( $\mathrm{I} \mathrm{cm}$ diam.) of Whatman $3 \mathrm{MM}$ filter paper which was then dried and counted. The concentration of ${ }^{32} \mathrm{PO}_{4}{ }^{3-}$ in the extracts was estimated by the method of Sugino \& Miyoshi (1964). Intracellular acid-soluble organic [ $\left.{ }^{32} \mathrm{P}\right]$ phosphate was calculated as the difference between total $\left[{ }^{32} \mathrm{P}\right]$ phosphate and ${ }^{32} \mathrm{PO}_{4}{ }^{3-}$.

Thin-layer chromatography. The intracellular acid-soluble pool (in $20 \mu$ l samples) was resolved by thin-layer chromatography on PEI-cellulose plates $(20 \times 20 \mathrm{~cm})$ using a modification of the method of Neuhard, Randerath \& Randerath (1965). Mixtures of CMP, CDP, CTP, GMP, GDP, and GTP were used as markers. Chromatograms were developed at $20^{\circ} \mathrm{C}$ with $0.13 \mathrm{M}-\mathrm{LiCl} / 2 \mathrm{M}$-formic acid $(\mathrm{I}: \mathrm{I}, \mathrm{v} / \mathrm{v}$ ) to $\mathrm{I} 5 \mathrm{~cm}$ above the origin. Plates were then dried and developed in the same direction with $\mathrm{I} M-\mathrm{LiCl} / 2 \mathrm{M}-$ formic acid (I:I, v/v) to the distance moved by CDP spots (about $6 \mathrm{~cm}$ above the origin). Plates were dried and then examined under incident u.v. light. The surface of each plate was divided into four zones corresponding to compounds migrating faster than CMP (i.e. $\mathrm{NAD}^{+}, \mathrm{NADP}^{+}$and sugar phosphates), mononucleotides, dinucleotides and trinucleotides. The cellulose powder of 
each zone was scraped into a separate vial and the ${ }^{32} \mathrm{P}$ radioactivity was counted. Since $\mathrm{PO}_{4}{ }^{3-}$ co-chromatographed with nucleoside diphosphates, the radioactivity of ${ }^{32} \mathrm{PO}_{4}{ }^{3-}$ in the total acid-soluble fraction was subtracted from that of ${ }^{32} \mathrm{P}$ in the nucleoside diphosphate zone.

Analytical methods. Respiration was measured with an oxygen electrode (Yellow Springs Instruments, Yellow Springs, Ohio, U.S.A.) at $30^{\circ} \mathrm{C}$ unless otherwise stated.

Radioactivity was measured in a Packard Tri-Carb liquid scintillation counter using 2,5-bis-(5-t-butylbenzoxazol-2-yl)thiophene (BBOT) in toluene $(0.4 \%, \mathrm{w} / \mathrm{v})$ as scintillator.

The concentrations of $\mathrm{Na}^{+}$and $\mathrm{K}^{+}$were determined in a Hitachi 204 atomic absorption spectrophotometer.

\section{RESULTS}

\section{$\mathrm{Na}^{+}$-dependence of energy-linked functions}

The effects of $\mathrm{Na}^{+}$on transport and motility as measurable energy-linked functions of intact cells were tested. All transport systems are apparently $\mathrm{Na}^{+}$-dependent (Fig. I).

Incubation of organisms under $\mathrm{Na}^{+}$- and $\mathrm{K}^{+}$-deficient conditions for several hours at $0^{\circ} \mathrm{C}$ caused partial loss of intracellular $\mathrm{K}^{+}$. Growth of such partially $\mathrm{K}^{+}$-depleted organisms began after a 30 to 40 min lag period when incubated with $\mathrm{Na}^{+}$and $\mathrm{K}^{+}$. The $\mathrm{K}^{+}$content of the organisms was then restored to the original intracellular level (Fig. I $a$ ). However, this net accumulation of the cation did not take place under $\mathrm{Na}^{+}$-deficient conditions.

The rate of glutamate uptake by the $\mathrm{Na}^{+}$-deficient organisms was initially about $10 \%$ of the rate exhibited by those with excess $\mathrm{Na}^{+}$and gradually slowed down (Fig. I $b$ ). A similar result was obtained for leucine uptake.

Phosphate uptake by the $\mathrm{Na}^{+}$-deficient cells initially proceeded at a rate less than $5 \%$ of that by organisms with excess $\mathrm{Na}^{+}$and stopped after $15 \mathrm{~min}$ incubation (Fig. I c). This cannot be ascribed to growth of cells incubated with $\mathrm{Na}^{+}$, because the time of incubation (Io min) was short with respect to the culture doubling time (6o $\mathrm{min}$ ).

Pseudomonas stutzeri is highly motile (Palleroni et al., I970). Since a low level of energygenerating metabolism is sufficient to support motility of bacteria (Adler \& Templeton, I970), we tested whether cells retained their motility under $\mathrm{Na}^{+}$-deficient conditions. Small drops of bacterial suspension with and without added $\mathrm{Na}^{+}$were observed by dark-field microscopy. The organisms with $\mathrm{Na}^{+}$remained vigorously motile 10 min after preparation of the drop, whereas movement of the $\mathrm{Na}^{+}$-deficient organisms was initially sluggish but became faster on adding $\mathrm{Na}^{+}$.

\section{Effect of $\mathrm{Na}^{+}$on phosphate metabolism}

Under the conditions in which the data in Fig. I $(c)$ were obtained, more than $80 \%$ of $\mathrm{PO}_{4}{ }^{3-}$ taken up by the bacteria was in the acid-soluble form. Longer incubation led to increased incorporation into the acid-insoluble form. The distribution of ${ }^{32} \mathrm{PO}_{4}{ }^{3-}$ into different acid-soluble pools was therefore measured (Fig. 2). There was rapid turnover and synthesis of the nucleotide pool in the presence of $\mathrm{Na}^{+}$. Addition of $\mathrm{Na}^{+}$elicited rapid $\mathrm{PO}_{4}{ }^{3-}$ incorporation into nucleoside triphosphate and nucleoside diphosphate fractions without appreciable lag, while incorporation into other fractions followed a lag period. During the initial few minutes, about three-quarters of the incorporated $\mathrm{PO}_{4}{ }^{3-}$ went into nucleoside di- and triphosphates. 

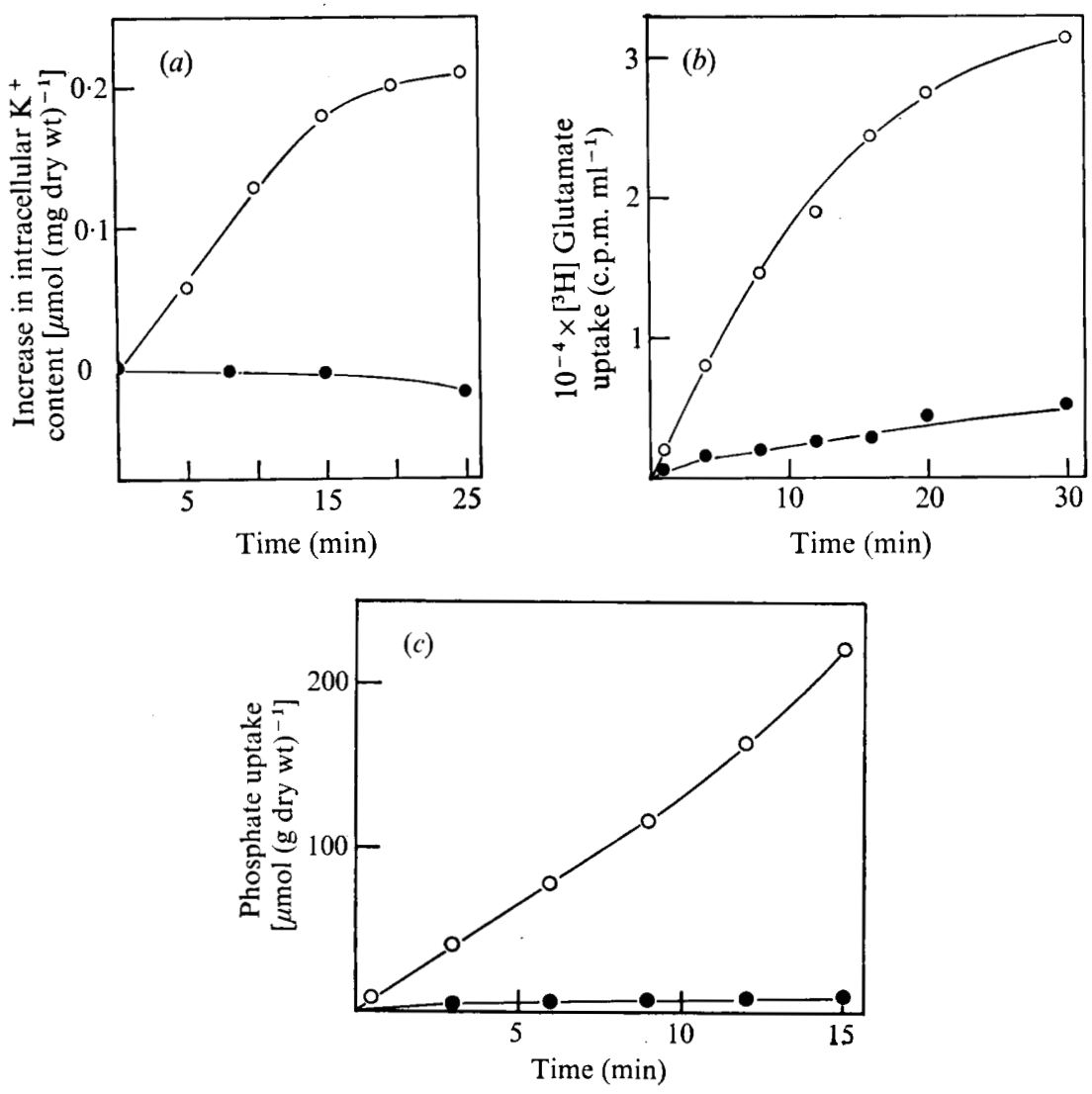

Fig. I. Effect of $\mathrm{Na}^{+}$on uptake of $(a) \mathrm{K}^{+},(b)$ glutamate, and (c) phosphate: $\bigcirc$, medium supplemented with $5 \mathrm{mM}-\mathrm{NaCl} ; \boldsymbol{\bullet}, \mathrm{Na}^{+}$-deficient control.

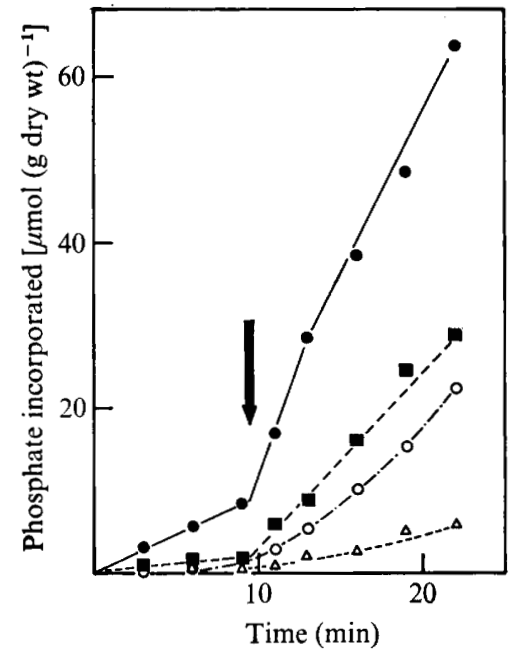

Fig. 2

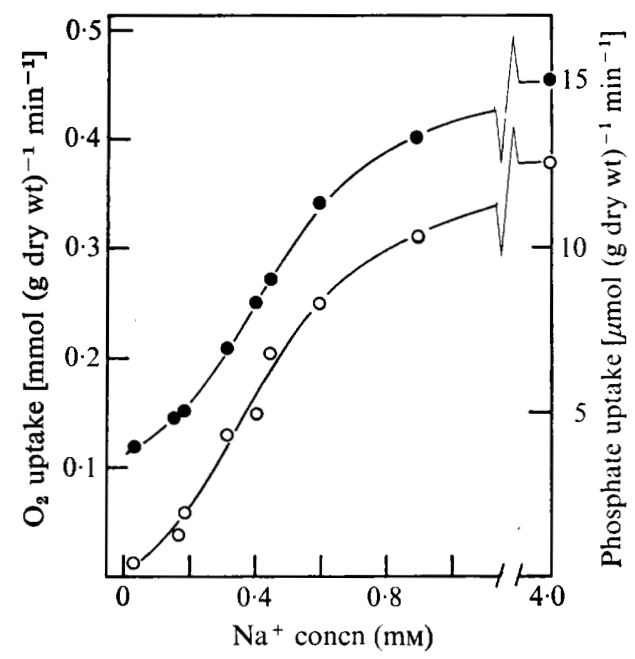

Fig. 3

Fig. 2. Incorporation of $\mathrm{PO}_{4}{ }^{3-}$ into the intracellular nucleotide pool. $\mathrm{PO}_{4}{ }^{3-}$ uptake was measured in TLG medium plus $5 \mathrm{mM}-\mathrm{KCl}$ and $0.1 \mathrm{~mm}^{32} \mathrm{PO}_{4}{ }^{3-}\left(400 \mu \mathrm{Ci} \mathrm{ml}{ }^{-1}\right)$ at $30^{\circ} \mathrm{C}$ as described in Methods. The arrow indicates time of addition of $5 \mathrm{~mm}-\mathrm{NaCl}$. Nucleoside triphosphates (0), diphosphates $(\mathbb{a})$ and monophosphates $(O)$ and other compounds $(\triangle)$.

Fig. 3. Response to $\mathrm{Na}^{+}$of respiration (O) and phosphate uptake (O) in TLG medium plus $5 \mathrm{~mm}-\mathrm{KCl}$ and $\mathrm{I} \mathrm{mM}^{32} \mathrm{PO}_{4}{ }^{3-}\left(20 \mu \mathrm{Ci} \mathrm{ml}^{-1}\right)$ at $30^{\circ} \mathrm{C}$. 
Table I. Effect of temperature on Hill plot parameters of $\mathrm{Na}^{+}$-dependent respiration

The results were from two independent experiments, one of which gave the results shown in Fig. 4.

$\begin{array}{ccc}\begin{array}{c}\text { Temperature } \\ \left({ }^{\circ} \mathrm{C}\right)\end{array} & \begin{array}{c}\text { Hill coefficient } \\ (n)\end{array} & \begin{array}{c}\mathrm{Na}^{+} \text {concentration (mM) giving half } \\ \text { max. activation, }[\mathrm{S}]_{0.5}\end{array} \\ 23 & 1 \cdot 89,1 \cdot 79 & 0.33,0.42 \\ 30 & 2 \cdot 27,2.40 & 0.47,0.48 \\ 37 & 2.62,3.25 & 0.75,0.76\end{array}$

Kinetics of coupling of respiration to phosphate uptake

Respiration and $\mathrm{PO}_{4}{ }^{3-}$ uptake rates were simultaneously enhanced in a sigmoidal fashion with increasing $\mathrm{Na}^{+}$concentration (Fig. 3). However, the respiration rate in the absence of $\mathrm{Na}^{+}$was about a quarter of the maximum rate whereas the corresponding $\mathrm{PO}_{4}{ }^{3-}$ uptake rate was negligible. This suggests that $\mathrm{PO}_{4}{ }^{3-}$ uptake is coupled to respiration only in the presence of $\mathrm{Na}^{+}$. The coupling efficiency increases with cation concentration, the maximum efficiency being attained above $2 \mathrm{mM}$.

\section{Effect of temperature on $\mathrm{Na}^{+}$-activated respiration}

Growth rate, like respiration rate, is a sigmoidal function of $\mathrm{Na}^{+}$concentration (Kodama \& Taniguchi, 1976), suggesting that activation of respiration by $\mathrm{Na}^{+}$is a cooperative phenomenon. The kinetics of $\mathrm{Na}^{+}$-activated respiration were therefore studied at different temperatures. At each temperature tested, the respiration rate with excess $\mathrm{Na}^{+}$was three or four times that without added $\mathrm{Na}^{+}$and the curve was sigmoidal (Fig. 4). When Hill plots were made of the $\mathrm{Na}^{+}$-dependent respiration rates (the difference between the rates with and without added $\mathrm{Na}^{+}$), a straight line with a slope greater than I was obtained at each temperature. The line became steeper and shifted towards high $\mathrm{Na}^{+}$concentration as temperature increased (Table I). Thus, the cooperativity of the response of the respiratory system to $\mathrm{Na}^{+}$was intensified at higher temperatures.

\section{Inhibitor studies}

The effects of various inhibitors on respiration were studied under $\mathrm{Na}^{+}$-deficient conditions and with excess $\mathrm{Na}^{+}$. Inhibition of respiration by polymyxin $\mathrm{B}$ was the most remarkable because it was altered by $\mathrm{Na}^{+}$(Fig. 5). Although the curves for inhibition with and without added $\mathrm{Na}^{+}$were similar, the curve with $\mathrm{Na}^{+}$was shifted to lower concentrations of the antibiotic, indicating that in the presence of $\mathrm{Na}^{+}$the respiratory system is more sensitive to polymyxin $B$. The sensitivity to other effective inhibitors of respiration, such as azide and cyanide, was the same with and without added $\mathrm{Na}^{+}$.

Table 2 summarizes the effect of uncouplers of oxidative phosphorylation on respiration under different cation conditions. Low concentrations of FCCP and dinitrophenol (DNP) stimulated respiration in the absence of either $\mathrm{Na}^{+}$or $\mathrm{K}^{+}$. In contrast, they had no effect when both cations were present. However, $\mathrm{PO}_{4}{ }^{3-}$ uptake which reflects energy-linked metabolism was strongly inhibited, suggesting that $\mathrm{Na}^{+}$deficiency retards energy-linked functions as well as respiration. 


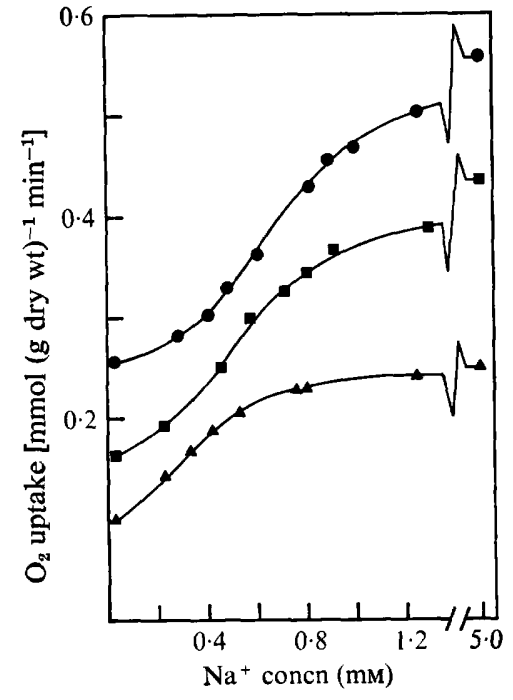

Fig. 4

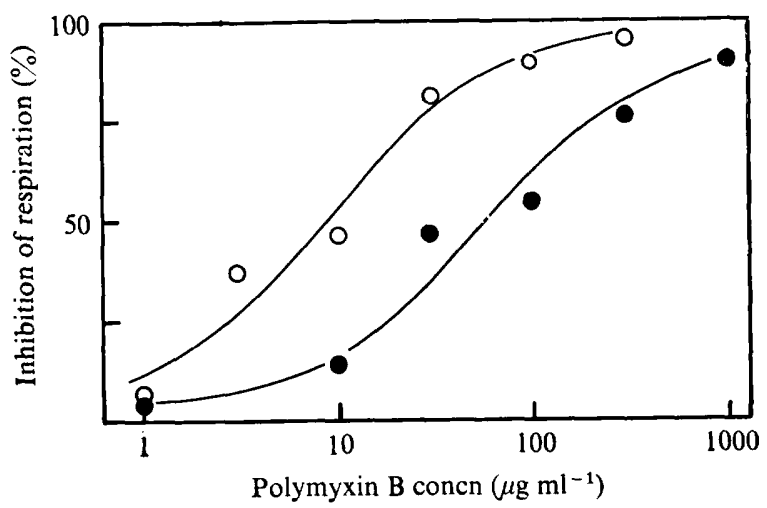

Fig. 5

Fig. 4. Effect of temperature on respiration at different $\mathrm{Na}^{+}$concentrations in TLGP medium plus $5 \mathrm{~mm}-\mathrm{KCl}: 0,37^{\circ} \mathrm{C} ; \mathbf{\square}, 30^{\circ} \mathrm{C} ; \boldsymbol{\Delta}, 23^{\circ} \mathrm{C}$.

Fig. 5. Inhibition of respiration by polymyxin $\mathrm{B}$ in the presence of $5 \mathrm{mM}-\mathrm{NaCl}(\mathrm{O})$ and in the absence of added $\mathrm{Na}^{+}(\bullet)$. Respiration was measured in TLGP medium plus $5 \mathrm{mM}-\mathrm{KCl}$ at $30^{\circ} \mathrm{C}$.

\section{Table 2. Effect of uncouplers on respiration and phosphate uptake}

Respiration and phosphate uptake were measured in TLG medium supplemented with I $\mathrm{mM}^{-32} \mathrm{PO}_{4}{ }^{3-}\left(35 \mu \mathrm{Ci} \mathrm{ml}{ }^{-1}\right)$. The cation concentration was $5 \mathrm{~mm}$.

\begin{tabular}{|c|c|c|c|c|}
\hline \multirow[b]{2}{*}{ Uncouplers } & \multicolumn{2}{|c|}{ Ionic conditions } & \multirow{2}{*}{$\begin{array}{c}\text { Stimulation of respiration } \\
(\%)\end{array}$} & \multirow{2}{*}{$\begin{array}{c}\text { Inhibition of phosphate uptake } \\
(\%)\end{array}$} \\
\hline & $\mathrm{Na}^{+}$ & $\mathrm{K}^{+}$ & & \\
\hline \multirow[t]{3}{*}{ FCCP $(3 \mu \mathrm{M})$} & + & + & 0 & 74 \\
\hline & + & - & 54 & NT \\
\hline & - & + & 30 & NT \\
\hline \multirow[t]{2}{*}{$\operatorname{DNP}(100 \mu \mathrm{M})$} & + & + & 0 & 80 \\
\hline & + & - & 43 & NT \\
\hline
\end{tabular}

\section{DISCUSSION}

$\mathrm{Na}^{+}$elicits multiple effects in cation-deficient $P$. stutzeri. Since these effects can be related to functions of the cytoplasmic membrane which performs energy transduction, we conclude that $\mathrm{Na}^{+}$exerts its primary effect on the membrane in such a way that energy stored as the energized state of the membrane can be used to drive ATP synthesis, active transport, cellular motility and other energy-linked processes. The following three lines of evidence support this conclusion.

I. The activation of respiration and phosphate uptake exhibits sigmoidal kinetics with respect to $\mathrm{Na}^{+}$concentration. This suggests cooperative behaviour or involvement of a highly organized structure, presumably through multiple interacting $\mathrm{Na}^{+}$-binding sites in the cytoplasmic membrane. Furthermore, the response of respiration to $\mathrm{Na}^{+}$was temperaturedependent. Conformations of functional proteins and their interactions in the membrane are known to be constrained in part by the viscosity of lipids which are in a fluid state in 
membrane structures (Singer \& Nicolson, 1972). Alteration of the fluidity of the lipid phase by a temperature change would be expected to modify the interactions between membrane proteins, resulting in altered kinetic characteristics of functions inherent in the membrane.

2. Increase in the sensitivity of respiration to polymyxin $\mathrm{B}$ in the presence of $\mathrm{Na}^{+}$suggests a conformational change in the cytoplasmic membrane accompanied by energetic activation. The antibiotic affects the permeability barriers of Gram-negative bacteria (Newton, 1956). According to HsuChen \& Feingold (1973), it interacts selectively with phosphatidyl ethanolamine and is thought to cause drastic perturbations between the lipid molecules. Thus, the higher sensitivity to polymyxin $\mathrm{B}$ in the presence of $\mathrm{Na}^{+}$could suggest that the cation-binding to the membrane affects the packing of the lipid constituents so that the target molecules become more accessible to the antibiotic and/or that the lipid phase as a whole is rendered more labile to its disorganizing action.

3. The evidence for the existence of some energized state of the membrane comes from the fact that FCCP and DNP stimulated respiration of the $\mathrm{Na}^{+}$-deficient cells which could not perform energy-linked functions. These uncouplers influence several functions of the bacterial membrane, for example stimulation of respiration, active transport, oxidative phosphorylation, energy-dependent transhydrogenase (Harold, 1972) and cellular motility (Larsen et al., 1974). These effects are now thought to be due to the ability of uncouplers to dissipate the energized state of the cytoplasmic membrane. Thus, the low respiration rate of $P$. stutzeri may indicate restriction of respiration resulting from a blockade of the use of energy stored as the energized state of the membrane for energy-linked functions. Perhaps the uncouplers increase respiration by 'short-circuiting' the energized state under the $\mathrm{Na}^{+}$- or $\mathrm{K}^{+}$-deficient conditions.

We thank Professor K. Okuda for his interest and support. We are also grateful to Professor S. Osawa and Dr S. Shimizu for enabling us to carry out experiments with radioisotopes. This work was supported in part by research grants from the Japanese Ministry of Education, Science and Culture and a grant from the Yakuruto Central Research Institute.

\section{REFERENCES}

AdLeR, J. \& TEMPleton, B. (1970). The effect of environmental conditions on the motility of Escherichia coli. Journal of General Microbiology 46, 175-184.

Fiske, C. H. \& SubbaRow, Y. (I925). The colorimetric determination of phosphorus. Journal of Biological Chemistry 66, 375-400.

HAROLD, F. M. (1972). Conservation and transformation of energy by bacterial membranes. Bacteriological Reviews 36, 172-230.

HsuChen, C.-C. \& Feingold, D. S. (I973). The mechanism of polymyxin B action and specificity toward biological membranes. Biochemistry 12, 2 I05-2 I I I.

Kodama, T. \& TANIGUCHI, S. (I976). Sodium-dependent growth and respiration of a nonhalophilic bacterium, Pseudomonas stutzeri. Journal of General Microbiology 96, 17-24.

Kodama, T., Shimada, K. \& Mori, T. (1969). Studies on anaerobic biphasic growth of a denitrifying bacterium, Pseudomonas stutzeri. Plant and Cell Physiology 10, 855-865.

Larsen, S. H., Adler, J., Gargus, J. J. \& HogG, R. W. (I974). Chemochemical coupling without ATP: the source of energy for motility and chemotaxis in bacteria. Proceedings of the National Academy of Sciences of the United States of America 71, 1239-1 243.

Neuhard, J., Randerath, E. \& Randerath, K. (1965). Ion-exchange thin-layer chromatography. XIII. Resolution of complex nucleoside triphosphate mixtures. Analytical Biochemistry 13, 2 I I-222.

Newton, B. A. (1956). The properties and mode of action of the polymyxins. Bacteriological Reviews 20 , I4-27.

Palleroni, N. J., Doudoroff, M., Stanier, R. Y., Salánes, R. E. \& Mandel, M. (i970). Taxonomy of the aerobic pseudomonads: the properties of the Pseudomonas stutzeri group. Journal of General Microbiology 60, 2 I 5-23I. 
SINGER, S. J. \& NICOLSON, G. L. (1972). The fluid mosaic model of the structure of cell membranes. Science I75, 720-73I.

Sistrom, W. R. (1960). A requirement for sodium in the growth of Rhodopseudomonas spheroides. Journal of General Microbiology 22, 778-785.

Sugino, Y. \& MrYoshi, Y. (1964). The specific precipitation of orthophosphate and some biochemical applications. Journal of Biological Chemistry 239, 2360-2364. 